Taylor \& Francis Inc.

ISSN: 1548-7760

DOI: $10.1080 / 15487760590953939$

\title{
Creating Hope Through Employment for People Who are Homeless or in Transitional Housing
}

\author{
JOE MARRONE*1 \\ ${ }^{1}$ Senior Program Manager, Public Policy Institute for Community Inclusion, Boston, Massachusetts, USA. \\ *Correspondence: JOE MARRONE, Northwest Office, 4517 NE 39th Ave, Portland, OR, 97211-8124, \\ USA, E-mail: jm61947(âa aol com
}

Persons with significant disabilities, especially those with problems relating to mental illness and/or substance abuse, face numerous challenges in securing employment. The program described in this article, Hope, Vocations, Progress (HVP) of Columbia River Mental Health Services (CRMHS) in Vancouver, WA, represents an aggressive strategy to facilitate the entry into work for persons with significant disabilities of mental illness and/or substance abuse, who also are in need of shelter, transitional housing, and other life supports. HVP was funded under a Rehabilitation Services Administration (RSA) demonstration grant and includes as its key partners a comprehensive community mental health center, a transitional housing program for women who are exoffenders, and a homeless shelter system. The program design is examined and program results through 39 months of a 60 -month cycle are provided. The author examines the impact of the program to date, its strengths and weaknesses in relation to evidence-based practice models of supported employment, and makes recommendations for further areas of research and inquiry

Keywords: Ex-offenders: Homelessness: Substance abuse; Supported employment.

Persons with significant disabilities, especially those with problems relating to mental illness and/or substance abuse, did not benefit as much as others from the booming economy of the 1990s or the advent of the American's with Disabilities Act (Burkhauser \& Stapleton, 2004). Furthermore, they continue to face significant employment barriers in the face of the faltering economy of the last few years (Burkhauser \& Stapleton, 2004; Burkhauser, Daly, \& Houtenville, 2000 ). It has become increasingly clear that unemployment is not a barrier that can be surmounted in isolation. Rather, unemployment is one strand in a web of challenges faced by these individuals, and success in employment can be achieved as one component in tandem with stability and health in life.

The program described in this article, HVP of CRMHS in Vancouver, WA, represents an aggressive strategy to facilitate the entry into work for persons with significant disabilities of mental illness and/or substance abuse, who also are in need of shelter or transitional housing in addition to other life supports. It also represents an important link with a wide range of partners including, local community mental health system of care, transitional housing and shelter resources, state department of Vocational Rehabilitation (VR) office, One Stop Career Center, local Washington State social services offices, who administer Temporary Assistance for Needy Families (TANF) and General Assistance funds, community college, and local employers. The parent agency, CRMHS, is a large nonprofit community mental health center that is the major provider of community mental health services to Clark County, WA residents. CRMHS offers a large array of services that include outpatient clinics, case management, residential facilities, case 
managed housing, mobile crisis response, medication management, and substance abuse treatment. It operates 13 service sites, has an operating budget of $11+$ million dollars, and over 250 full-time equivalent staff.

HVP was first developed in $200 \mathrm{I}$ under the aegis of a federal RSA Special Projects Demonstration Grant authority. It represents an attempt by a local consortium in Clark County, led by CRMHS, to integrate proven approaches to supporting persons with disabilities of mental illness and/or substance abuse in entering employment while addressing the needs of people who are homeless or in transitional housing. This population has not heretofore been well served by a more traditional approach to employment placement and supports. This project brought together local groups that have a strong presence in Clark County, WA.

The HVP demonstration was projected to serve 250 persons with significant psychiatric disabilities (with at least 75 succeeding in obtaining employment). Individuals were to become employed in a variety of jobs leading to career advancement and increased economic independence using a mentor, peer supports, accommodations, and career development design. Also, project resources were to be used to develop a curriculum of "in vivo," short-term, human service trainings for 10 participants a year ( 50 over five years) in local transitional housing programs run by the grantees.

The enrollees represented groups that have traditionally been underrepresented in the public VR system. The project developers proposed a key innovation, the integration of a variety of approaches into a seamless system of services. These services included the extensive involvement of local community organizations, the combination of a local employment services program (used by the mental health system of care as well as public VR), and two local transitional and shelter housing programs that address the needs of the whole person using natural and community resources. Thus, the program sought to combine effective strategies to meet the challenge of supporting persons with significant disabilities in entering and advancing in employment settings.

The intent of the article is to provide descriptive data that will act as a formative evaluation of the initial implementation of an innovative service intervention design funded by a federal demonstration grant. The project development and initiation is depicted and key mid-project (39 months into a 60-month demonstration cycle) statistical data is offered. Two client case studies are also presented to illustrate, qualitatively, the types of services and process encountered by program clients. Finally, program accomplishments achieved and obstacles encountered to date are noted

\section{BACKGROUND}

Across the country, model programs in employment have documented that persons with significant disabilities can move into integrated employment settings when appropriate support and training are provided (Bond, 2004; Salyers, Becker, Drake, Torrey, \& Wyzik, 2004). Rapid job entry, transitional work experience (time-limited, entry-level jobs for purposes of work experience rather than career development), intensive case management (relying on direct support and involvement rather than brokering services), and wraparound services (marshalling multiple systems to focus comprehensively on the individual's needs rather than assisting the person to access these services individually) have also proven effective (Becker et al., 2001; Drake et al., 2001; Marrone, 1993; MDRC, 2001; Phillips et al., 200I, Shaheen, Williams, \& Dennis, 2003).

There are a multitude of research studies, reports, and anecdotal data that have focused on the intertwined issues of poverty, unemployment, disability, substance abuse, and homelessness (Ball \& Havassy, 1984; Johnsen et al., 1999; McMurray-Avila, Gelberg, \& Breakey, 1998). For example, in a 1999 study, $66 \%$ of homeless clients reported one or more problems related to mental illness or substance abuse during the month prior to the study (Urban Institute, 1999). 
According to the President's Commission report (2003), individuals with psychiatric disabilities are over-represented among the homeless. Of more than two million adults in the United States with at least one episode of homelessness, $46 \%$ reported having had a mental health problem. Nationally, the National Alliance for the Mentally Ill (NAMI) has estimated that there are 110,000 persons with mental illnesses that experience chronic homelessness (NAMI, 2001). In another document, Shaheen, Williams, \& Dennis (2003) cite somewhat different figures gleaned from a variety of sources in the 1990s: "On a given day, an estimated 600,000 people are homeless, approximately one-third have a serious mental illness, and about one-sixth suffer from co-occurring mental illness and substance use disorders" (p. 1). Examining individuals who are homeless from another perspective, a recent study found that as many as one-half to three-fourths have diagnoses of alcohol or other drug dependence. The social costs associated with untreated substance disorder are higher among homeless than nonhomeless persons (Wenzel, Ebener, Koegel, \& Gelberg, 1996). Also, persons who have a mental illness and are homeless were significantly more likely than those without mental illness to receive Supplemental Security Income (SSI), Social Security Disability Insurance (SSDI), Veterans Administration (VA) disability benefits, or Medicaid (Sullivan, Burnam, Koegel, \& Hollenberg, 2000).

In a recent study of homelessness services, clients were asked to name the three things they needed most "right now," and also to identify the single most important thing keeping them in a homeless condition. Help finding a job was the most frequently cited need by almost half the respondents (42\%), followed by help finding affordable housing, and assistance with paying rent, mortgage, or utilities in relation to securing permanent housing (Lam \& Rosenheck, 2000). Klinkenberg and Calsyn (1996) found that informal support variables and case management have been associated with reduced recidivism. In addition, the criminal justice system has an overrepresentation of individuals with psychiatric disabilities. In the NAMI Treatment/Recovery Information and Advocacy Database report (Hall, Graf, Fitzpatrick, Lane, \& Birkel, 2003, p. 22), $44 \%$ of respondents to the survey reported being arrested or detained in their lifetime. The President's Commission (2003) reports that $7 \%$ of those who are incarcerated have serious psychiatric disabilities, which is three to four times that of the general population. Other studies cite higher figures with an estimated $8-16 \%$ of the prison population and $10 \%$ of the jail population having at least one identified serious mental disorder and being in need of treatment (Harlow, 1998; Lurigio, 2001)

Many traditional programs have been unsuccessful in assisting participants with the variety of problems the group targeted in this program face. Yet, research has demonstrated that there are promising, evidence-based practices that can make a difference. Such practices include personcentered career planning, on-site support from peers, family members, and mentors, assisting people to make individual changes based on their commitment to life change, "in vivo" assessment and training, and integrating employment services with more clinically oriented treatment services and housing supports offered by shelter and transitional housing providers (Belcher \& Ephross, 1989; Becker, Torrey, Toscano, Wyzik, \& Fox, 1998; Bond, Drake, Becker, $\&$ Mueser, 1999; Long \& Van Tosh, 1998; Oakley \& Dennis, 1996). This project integrated many of these "best practice" models into its design.

\section{CLEARVIEW EMPLOYMENT SERVICES MODEL}

The program model incorporated many of these elements within a local community partnership that included mental health, substance abuse treatment, housing, and employment providers that focused on people with significant disabilities. The purpose of the HVP project is to provide a range of services leading to employment for individuals with significant disabilities of mental illness or co-occurring disorders who are in need of shelter and transitional housing. The services provided included individual planning, "in vivo" training, work experience, coordination of 
resources, access to natural supports in work and community settings, and enhancement of the capacity of local providers. Through its employment service division, Clearview Employment Services, CRMHS has had extensive experience serving consumers with significant disabilities Clearview is funded by mental health, public VR, and Welfare-to-Work funding. The Clearview approach is heavily based on the structures and values of person-centered planning, the traditions associated with Supported Employment, and more recently in the psychiatric world, with the Individual Placement and Support evidence-based practice (Bond, 1998). The Clearview system that formed the base of the HVP model is rooted in open and easy access, fast-paced career exploration and resource groups, individual job development, and long-term support, using professional and community resources. In addition, CRMHS operates a 26-bed rehabilitation transitional housing program for people with disabilities of mental illness, the majority of whom were recently discharged from psychiatric hospitals. The transitional housing program incorporates rehabilitation staff who assist residents in transitioning to more permanent housing and jobs. Clearview's primary partners in this project were YW Housing and SHARE House. YW Housing is an agency whose core mission is providing transitional housing to homeless or wouldbe homeless women, as well as women involved with the criminal justice system who have children. The mission of SHARE House is to assist those in need of shelter to address their emergency needs and then, through case management, secure permanent housing and pursue their long-term goals and needs. Interestingly, in project development, both of these collaborators were offered the opportunity to receive direct grant funding through subcontracts with CRMHS but each rejected that option in lieu of regular "out-stationing" of Clearview HVP staff at their respective sites. "Out-stationing" is the permanent assignment of vocational staff employed by Clearview to the independently operated YW Housing and SHARE House

The need for better integrated services for individuals with mental illness who are also homeless that leads to employment and career advancement is palpable. The CRMHS residential services were able to incorporate some rehabilitation approaches, though they were not fully funded through the local system of care. SHARE and YW Housing did not have the luxury of any rehabilitation staffing, yet both identified the importance of providing more on-site vocational rehabilitation expertise to benefit their respective clientele. Traditional partnership links to mental health day services have many salubrious effects for this population; however, without more intense involvement at a level this program model demonstrates, the effect on employment and community reintegration is less evident (Caton, Wyatt, Grunberg, \& Felix, 1990; Drake et al., 2001).

The design of the project incorporated a multi-faceted structure that brought together housing, community mental health, employment services, and rehabilitation resources with "state-of-theart" rehabilitation practitioner technology. Homelessness exacerbates the already insidious effects of significant disability attributed to impairments of mental illness, substance abuse, and cooccurring disorders. It has not been unusual over the years for traditional public and private vocational rehabilitation providers to exclude many potential clients from direct placement services until their housing needs have been addressed. This project seeks to provide vocational services concomitant with assistance to achieve permanent housing from the partners in this endeavor.

The HVP project, operated by Clearview employment services, began in October 2001. HVP uses a variety of approaches (identified below) to address the concerns of persons with significant disabilities who are homeless or in transitional housing and have disabilities related to mental illness, substance abuse, and co-occurring disorders such as permanent residence, health care, personal assistance, social isolation, stress, etc. Linking local housing resources, community mental health, vocational rehabilitation, and One-Stop Career Centers together in this design offered a range of providers who are knowledgeable about community resources and needs, and 
individually skilled in addressing unique elements of those needs. (One Stop Careers Centers are funded by the Workforce Investment and provide in one location a wide range of federal, state, and local employment programs.) This network and the HVP program's approach to employment comprehensively addressed entry into employment for individuals with significant psychiatric disabilities, who were either homeless or in transitional housing.

The HVP project responds to the needs of this target popula-tion by:

- using no "pre" or "readiness" screening;

- using a person-centered employment and career planning approach in the assessment of interests and abilities and the design of service delivery;

- emphasizing rapid job entry and wraparound planning and supports as well as short-term training leading to employment in the health care/human services field;

- involving various community resources: a Community Mental Health Center, which is also a local community rehabilitation provider contracting with the state VR for employment services, a shelter serving homeless men, and a transitional living program for homeless women (a majority of whom also have felony convictions), a public housing authority, and a local public VR office;

- emphasizing capacity of housing and mental health staff to serve the target population;

- using peer and natural supports (peer support groups, personal networking for job acquisition, and housing/worksite mentors);

- using a personal change model to assist people with the most significant psychiatric disabilities take control of their personal transformation process;

- providing support from a program that assists consumers with co-occurring disorders; and

- developing solutions to employment barriers for people with the most significant disabilities involving mental health and/or substance abuse and who are homeless or in transitional housing.

Some specifics of the program process and design used in the HVP project are described.

\section{a. Recruitment and Enrollment}

Participants are identified through active outreach by collaborators and regularly scheduled orientations that are conducted multiple times, at multiple sites where clients reside or attend. Clearview's HVP staff are based at the shelters and transitional housing sites several days a week, in addition to conducting orientations. A "zero reject" model is used, except for the [potential] client's attendance at one of these orientation sessions. If a person expresses interest in HVP, an appointment is made with an HVP employment specialist to begin employment planning. If a client chooses not to attend the orientation, individual appointments are scheduled. Once the individual is recruited at the shelter or housing locations operated by the partners he or she meets with project personnel (family and friends can be involved as desired) to explain the project goals and objectives, the responsibility of project participants and staff, the process to be followed and the anticipated outcomes for the individual. Should the individual express an interest in becoming involved as an HVP client, then a specific staff member is assigned to facilitate the entry process for that person. HVP staff are out-stationed at both SHARE and YW Housing to make sure people are personally engaged, not merely referred, to an anonymous program. Regularly scheduled group orientation sessions are conducted as well as this personal outreach. 


\section{b. Initial Planning}

A person centered employment/career planning process, using creative brainstorming, group facilitation, and broadening of the network of people with whom they engage will be used, modifying material from an existing Exploring Work/Careers/Resources Group run by CRMHS in a project involving welfare clients with mental health problems. Clients are also offered a peer support group to focus on issues related to adapting to life outside of the transitional housing arrangements in which they currently reside.

The Employment Specialist is responsible for assisting the client throughout the process, by marshaling other resources on his/her behalf (including other treatment services available through the community mental health system of care, e.g., co-occurring disorder treatment), providing advice and sometimes guidance on community re-entry, advocating with more generalized employment resources, such as public VR or the One Stop Career Center, assisting ancillary staff involved with the client in understanding the role of employment as a path to positive life change for the clients, advocating within the mental health/ housing systems for the client, and serving as an ally throughout the client's progress through the program

The basic staffing pattern used in this HVP approach consists of: One FTE Peer Specialist, two FTE Employment Specialists, and one FTE Job Developer. Services are being provided to one men's homeless shelter, two family shelters, the women's ex-offender transitional housing program, the co-occurring disorder program at the community mental health facility, as well as individuals who are homeless and receive services from the community mental health center.

In essence, the HVP model combines the strong elements of personal empowerment and control described in the "Choose-Get-Keep" approach advocated by Danley and Anthony (1987) with the evidence-based "technology" of the IPS model advocated by Drake and colleagues (2001) at the Dartmouth Medical School. One element emphasized in the HVP approach that is less wellattended to in other models, such as "Choose Get Keep" or IPS, is the recognition that many clients with mental health problems erroneously feel (and are often supported by clinicians to feel) that employment causes stress that exacerbates serious mental illness or that people with mental health problems cannot overcome. Therefore, an essential component of the Clearview approach is the active "marketing" of employment as not just a possibility for people with mental illness, but one which generally strengthens them and helps them achieve a more valued citizenship role in society (Marrone \& Golowka, 2000). The full citizenship role includes some degree of financial self-reliance or self-sufficiency. This is the ability to acquire the financial resources to support one's self or at least contribute to one's own support, as opposed to relying solely on government support.

While there are a number of approaches to such an individual planning process, there are some broad basic principles that have been enunciated in the literature which the HVP project utilizes. These include (a) primary direction from the individual in shaping the planning process; (b) involvement of family members and friends; (c) focus on capacities and assets of the individual rather than on limitations; (d) emphasis on the settings, services, supports, and routines available in the community; and (e) planning that tolerates uncertainty, setbacks, false starts, and disagreement (Marrone, Hoff, \& Helm, 1997).

Each client is assigned an Employment Specialist who develops a Personal Career Plan, including coordinating a "Rally" (within 2 weeks of program entry) with a group of that person's choosing to assist in moving the plan forward. Three options related to the HVP project are:

1. Immediately look for a job based on that person's stated goals and interests

2. Assist the person in entering a one- to three-month transitional work experience. 
3. Assist the person in entering a two-week on-site skills training developed at the residential program that CRMHS operates. This training regimen focuses on basic skills required for entry into the human service/health care field, offering an opportunity for a two-week follow-up internship at CRMHS. Training is done by CRMHS Clearview Employment staff supported by grant and "in-kind" CRMHS staff already employed in the organization's residential programs.

\section{c. Service Delivery Components}

The staff on the project work as a team with each staff person, whatever their job title, being the "go to" problem solver and primary client contact for specific individuals in the program. Each of the team members is expected to be familiar with all program clients and engage in efforts on their behalf. Clients can opt to be involved in a 1-week long group emphasizing the importance of taking charge of your life and creating positive change.

\section{d. Specialized Consultation}

A final innovative feature of the project is the availability of specialized consultation services or clinical interventions for people with co-occurring disorders of mental health and substance abuse. CRMHS has a well-established program called the Center for Dual Diagnosis and Recovery (CDDR), which is funded through both mental health and substance abuse treatment resources. Its chief psychiatrist is a board certified addiction specialist who provides on-going clinical consultation to CDDR. CDDR staff and the Chief Psychiatrist are available to clients directly and provide project staff with specific consultation. This service is vital as, very often, as discussed above, the population to be served under this project is impaired by these dual problems

The processes described above are illustrated in the flow chart in Figure I below.

Figure 1 Hope, vocations, and progress model.

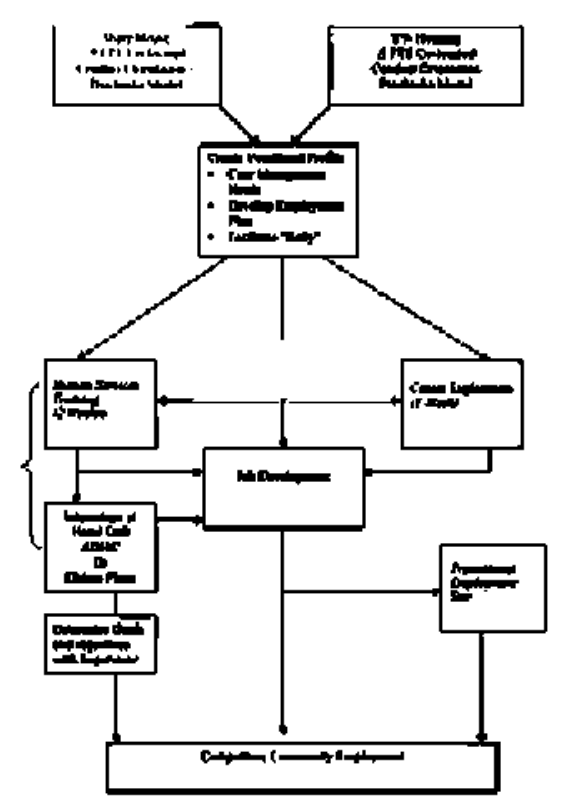

\section{CASE STUDIES}


To put a human face on the project and illustrate how clients of HVP might engage in and be assisted throughout the process, two case studies describing the situation and the HVP process as it affected two of its clients follow.

Case Study 1: Terry $M$. is a 38 year old woman with a 9 year old son. Terry has a history of serious mental illness, co-occurring substance abuse, and felony comvictions. She had been working for 6 years when her symptoms began to interfere significantly in her life. She worked in quality control at one of the major printing companies in Washington State. She had hoped to work her way up to sales, but her symptoms, which she self-medicated with alcohol and other substances, were getting worse. She knew welfare was there, but "just to go there was way overwhelming. impossible. "Terry did connect with the welfare office eventually and agreed to be treated at a hospital for her symptoms (3-day hospitalization).

Terry had a history of assaultive behovior against her mother for which she had been prosecuted. The judge remanded her for 2 years of mental health treatment instead of anger management. but, as she stated: "just because the court mandates mental heath services does not mean that facilities are required to provide mental heath services." Not being able to access effective treatment services, she went through more turmoil and began to use drugs. She put herself into the hospital again and upon discharge started receiving treatment services and became involved with the transitional residential program for women ex-offenders, YW Housing, one of the partners in the HVP program. She said that only after she had attacked her mother. gone to court, and put herself into the hospital had she become eligible for mental heath treatment interventions.

Terry started her employment service working with a job coach from her treatment provider (not CRMHS). but the process was not going very well. She started using the One-Stop Career Center, with its variety of employment programs and resources hoping that it would be more effective in helping her find work. Terry found the One-Stop physically intimidating and the array of services and supports overwhelming. She had 12 job interviews and succeeded in getting a job in the printing industry after the first interview. However, she lost that job because it did not accommodate her needs (e.g., flexible schedule/time to care for her son).

Clearview's HVP program came to the transitional housing unit run by YW Housing as part of its regular outreach, introduced the program, and offered residents an opportunity to be a part of the project. She said that Clearview was a "god-send. "She had been looking for work for 2 years and finally found an agency that could actually help her find employment. She said, "It was everything that I'd ever prayed for. "She felt that Clearview, in contrast to the One Stop, focused on her desires and needs and. in a practical vein. was successful in providing action not just talk.

Terry and her Clearview job coach met once a week. The job coach accompanied her to the welfare agency, and showed her how to advocate for herself. Terry participated in various trainings, including a career exploration and human service training from the HVP. Clearview also referred her to $V R$, which paid for the following services:

- Covered the costs for a mental health clinical assessment

- Helped Terry get her GED by paying for a one-month training at Sylvan Learning Center

- Paid for Terry's peer counselor certificate training

- Bought her clothes and a cell phone, and upgraded her computer/software.

HVP assisted Terry to succeed at these tasks through its person support function.

According to Terry, the MH agencies and VR worked very well together. Prior to getting services, Clearview organized a three-hour meeting. known as the HVP "rally." Participants included the 
caseworker from Terry's transitional housing agency, the $M H$ treatment counselor, the Clearview job coach. HVP Director, and Terry herself. The team looked at a "picture of Terry 's life" discussing negative experiences and challenges and identifying her strengths and the life skills she had learned. According to Terry, the meeting increased staff members' knowledge about her. her abilities, and future plans, goals, and aspirations. This in turn helped her develop a concrete vocational plan, including identifying her individual support needs.

In the process of working with Clearview, the HVP staff connected her with a group, organized by the ARC (formerly Association of Retarded Citizens). through which she participated in a oneyear training that taught individuals, among other things, how to advocate to the legislature. Terry also got involved in the Community Empowerment Project, a parent advocacy group for parents of youth with mental illness and became part of the project through her employment as a Peer Parent Partner. The only accommodation that Terry had on the job was the option of temporarily transferring her caseload to her HVP job coach while she was dealing with recovery issues.

Currently, Terry subcontracts with Clark County to work as a peer parent partner. As such. she supported parents who have children with mental illness, teaching them the skills that her job coach previously taught her (e.g., how to advocate for oneself). She accompanied parents to their different appointments, helped them access services, connected them with resources, etc. She was on call 24 hours. Terry said, "This [job] is unlike anything I've ever done before... I feel I'm just being paid for being myself and that I'm able to give back what was given to me ... and this is very healing for me." Terry had a caseload of five parents, two of whom had graduated from the family service program for whom she worked. She was only allowed to work up to 20 hours a week ( 3 hours with each client). The grant that funded her position has recently changed and she is currently in the process of getting certified as a Washington State Mental Health (MH) peer counselor.

Sharing her experiences with other people has become an important piece of her life. Terry spoke at a federal RSA conference in Washington, DC (in conjunction with HVP and staff) and also at a mental health/substance abuse co-occurring disorder conference in Yakima. WA. She wants to continue being a speaker and hopes to get paid enough to someday make it at least a part-time career.

Case Study 2: Linda $K$ is a 47-year-old woman who has been married for 25 years. She is a high school graduate who was a "stay at home" homemaker for 22 years and worked briefly as a housecleaner for a private company from 1996-1997. She has two grown children, a married daughter and a son, neither of whom she talks about very much. She did not report having had any mental health issues until 2 years ago when she attempted suicide due to a clinical depression and was admitted to one of the state psychiatric institutions in Washington State. She was institutionalized there for 9 months and reports nothing seemed to help her depression. Her doctors finally prescribed shock treatments and Linda began to "pull out of her depression" as she describes it.

Linda was discharged from the hospital and admitted to Elahan Place, the transitional rehabilitation housing program operated by CRMHS. She began to recover rapidly. Unfortunately her husband decided that he no longer wished to be married and filed for divorce. Instead of falling back into depression. Linda contacted Clearview Employment Services and began working with a vocational specialist there. Linda and the HVP program staff, working in conjunction with the small business consultant who is an integral part of HVP services, began the process of business ownership for Linda. Linda's goal was (and is) to own and operate her own housekeeping business. Linda was discharged from Elahan Place and moved to a shelter called Open House Ministries where she is waiting for her divorce to be finalized.

In the meantime she has established a regular and growing clientele for her own housecleaning 
business, Linda Jo House Cleaning. She has about six regular customers at this time and is very happy with how things are going. She may be able to get off SSI in the near future because between her business and alimony she will be self-sufficient. Linda reports to her HVP staff person that having the goal of business ownership coupled with employment to keep her busy and focused has been instrumental in her recovery.

\section{RESULTS}

Since the program's inception, the results have far exceeded projected expectations in most respects. The goals for the 5-year period were to engage 250 clients, develop 175 personal career plans or vocation profiles, and assist 75 participants to secure employment. In the period from 1 October 2001-31 December 2004, the results achieved in these areas have been 791 clients engaged (measured by attending orientations at the shelters and transitional housing sites), 543 participants developed vocational profiles with HVP staff, and 129 people either in shelters or transitional housing have secured employment. Of those 129 people, 93 have retained employment for over 90 days and 14 of those jobs have health insurance as a benefit. People who have become employed have averaged approximately 28 hours work per week with an average salary of over $\$ 8$ per hour (approximately $\$ 225$ weekly), and a range from $\$ 17.50$ to $\$ 6.90$ per hour. One hundred twenty-seven clients have a primary mental health diagnosis, 62 have a cooccurring mental health and substance abuse problem, and 303 have mental health problems and legal issues, including felony or misdemeanor convictions.

The program has far exceeded its goals in relation to its development as a grant funded demonstration program (as depicted in Table 1), but it has not performed as well as expected in its attempt to fully replicate evidence-based supported employment practice. From 1 October 2001-3I December 2004 (39 months or $65 \%$ of grant time), HVP achieved over $300 \%$ of its fiveyear goals in the areas of number of clients engaged and vocational profiles developed and over $170 \%$ of its five-year goals in clients employed. This deficit will be elaborated on further in the Discussion section.

TABLE 1 HVP statistical achievements (10/1/01-12/31/04)

HVP 60 month goal (10/1/01-Achievement-39 months $(65 \%$ Percent achieved as of 39 9/30/06) of time) months

\begin{tabular}{lll}
\hline 250 clients engaged & 793 clients engaged & $316 \%$ \\
150 vocational profiles & 543 vocational profiles & $310 \%$ \\
75 clients employed & 129 clients employed & $172 \%$
\end{tabular}

\section{DISCUSSION}

While the HVP project was not designed as a research project, it has demonstrated reasonable success with two groups of people often seen as problematic in terms of achieving employment success - people with mental health and/or substance abuse disabilities who are homeless, in transitional housing, or using homeless shelterservices. Thus the comprehensive model, incorporating many of the conditions of evidence based supported employment practices, appears worthy of further study and replication under more rigorous criteria suitable for scientific 
validation within the psychiatric rehabilitation field.

The HVP project has been able to provide supported employment using a well-integrated employment arm of a comprehensive publicly funded mental health center and the coordination of multiple systems of care (mental health, homeless services, corrections, substance abuse, and VR). The results to date of the HVP project compare somewhat less favorably with the employment outcomes reported in the evidence based practice literature. Yet, the program has shown impressive results in terms of attracting an extremely transient and difficult to engage group of people and very high 90-day job retention rate. The program has accomplished these significant milestones without any attempt at "readiness" screening, only using aggressive outreach several times a week at shelters, transitional residences, the mental health center, and a focused effort to actively encourage people to seek out employment and to engage them over a long period of time. The core elements of the design have included: person-centered employment and career planning; rapid job entry and wraparound planning and supports; comprehensively involving multiple community resources in planning, assessment, engagement, and employment services; using peer and natural supports; emphasizing the capacity of staff to assist people with significant disabilities take control of their personal transformation process; and the ability of individuals confronting the life barriers posed by such problems to effectively overcome them.

These accomplishments have been achieved while still facing many major systemic obstacles that typically occur in "real world," naturalistic settings rather than in more controlled research environments. These obstacles are in addition to the clinical challenges that disability poses to the clients served under HVP. Increased budget cuts within the public mental health system have reduced eligibility for counseling and therapeutic support services. Access to preventive dental and health care as well as access to psychiatric medications for HVP customers continues to be problems. Budget cuts in public assistance services and stricter eligibility requirements for cooccurring disabilities have impacted treatment services for this population. Involvement in employment activities has been a major programmatic shift for HVP housing partners (both their clients and staff) and Clearview/HVP Project staff have helped acculturate this system to work programming and expectations. Since the shelter partners in the project generally have a 30 -day time limit on residence (there are some limited extensions for program participants), there is an inherent tension in the HVP project's focus on person centered planning (the "Rally"), and the need to do rapid job development just to obtain any sort of subsistence level of employment before leaving the shelter.

Expanding to a broader service system beyond mental health and the VR systems that Clearview has been accustomed to navigating has brought additional challenges of setting up policies and procedures for new programs, and integrating new staff into an even broader program unit. The HVP effective program capacity is near its practical limit as the number of individuals seeking services has far exceeded expectations and the success of the project has spread to the community; yet, at the same time, other organizations such as the legal system and child support enforcement services have expressed the desire to expand similar services to their clientele.

As with client problems, the HVP/Clearview project has been proactive and assertive in seeking some solutions to these administrative policy issues. Regular HVP management meetings have been held to address consistency with procedures, change processes, review caseloads, coordinate services with employment personnel and housing personnel, and address individual clinical barriers. A monthly community agency training was developed to secure administrative assistance from stakeholders in addressing the challenges and barriers of the individuals that are served as well as to further activities around networking and resource mapping to identify additional community resources. HVP supervisors and management conduct ongoing regular staff development, training and orientation for both its own staff and other agencies involved. Active problem solving has continued to be facilitated by HVP projectmanagement and its program 
consultant (the author) through the Institute of Community Inclusion (ICI) as well as intense support from the mental health center senior management. CRMHS and Clearview staff have also participated with the Washington state legislative task force on services to nonfunded individuals who are in need of mental health and substance abuse treatment services. Finally, as part of the HVP program's goal of enduring systemic change, Clearview/HVP personnel and ICI continue to facilitate ongoing discussions about the differing philosophies of disparate systems engaged in the project: homeless advocates, criminal justice, mental health treatment, and public vocational rehabilitation in addition to the core psychiatric rehabilitation and employment staff of the HVP program itself.

Several areas of inquiry and improvement still present themselves even in the face of some excellent start-up work from the HVP program. Since the program was not evaluated with a control group or with an eye to scientific rigor, it could benefit from more detailed examination and program evaluation. Also, while the program collects demographic information on each of the clients, such as age, gender, and level of education, because of limitations of the agency's management information system structure, this information is not easily retrieved for program level analysis. As an example, it was not possible for the program administration to correlate employment and demographic data related to disability or referral source without resorting to a review of each individual case file. The program has done an outstanding job in recruiting clients, building hope, making concrete plans, and assisting many people with mental health and cooccurring disorders to find employment; nonetheless, there is still major room for improvement in finding higher paying, career enhancing employment for many of the individuals served rather than primarily entry-level jobs. While the 2-week entry level skills in health care/human service training built into the design has proven useful in the past, especially for those looking to become peer counselors within the mental health system, it may prove redundant as the state of Washington implements its own mandatory peer counselor certification track.

Two broader issues need further examination. The first issue entails programs striking a proper balance between quality and quantity in terms of available resources. Focusing only on quantitative outcomes without attention to quality of life issues may be unethical. If personcenteredness is to have any resonance beyond mere verbiage, then service delivery must focus on outcomes that reflect personal quality of life issues for those served. On the other hand, producing high-quality outcomes without affecting significant numbers of people is selfindulgent. Enduring system change involves both types of measures (Marrone \& Boeltzig, 2005). This is a conundrum that affects all employment assistance and many other human service programs in general. However, it is particularly relevant to a more detailed examination of the HVP program because one of the guiding philosophical tenets of the program is the need to promote employment to a wide variety of people with significant disabilities, even if they have not previously sought employment help. This flows from the concern that program management, staff, and ICI consultants all share, that mental health systems do not acknowledge the dangers that are attendant to long-term unemployment (Dooley, Catalano, \& Wilson, 1994; Kasl, Rodriguez, \& Lasch, 1998; Lennon, 1999). This fact is especially compelling in light of the absence of any valid scientific data that actively promoting employment is a precipitant of increased psychiatric symptomatology (Marrone, Tellier, DiGalbo, \& Taylor, in press). Indeed, there are a plethora of reasons why individuals with psychiatric disabilities should be strongly encouraged to pursue employment in their recovery because work often provides both preventive and ameliorative mental health benefits (Marrone \& Golowka, 2000).

Even though the program has far exceeded its goals in relation to its program application (Table 1), it has not performed as well as expected in respect to its evidence-based supported employment outcomes. This fall off is due both to inadequacies attributable to program design, project management, or staff skills as well as to the transient nature of the population targeted, 
who are often loosely attached to the human service community. The only element of the fidelity measures for evidence-based practice in supported employment that the Clearview HVP project does not rate highly on is the ratio of employment staff to clientele (Bond, Picone, Mauer, Fishbein, \& Stout, 2000). While the ideal ratio is 1 FTE employment staff to $18-22$ clients, the entire staffing of the HVP is only 4 FTEs (including employment specialists, a job developer, and a peer supporter) who have engaged over 500 clients in employment planning to date. There is excellent clinical integration philosophically and structurally as Clearview has strong backing from the executive leadership of CRMHS and has ongoing representation within all the clinical teams. Nevertheless, the ability to integrate rehabilitation and recovery thinking into actual practice by mental health clinicians remains somewhat of a problem at CRMHS as in many other mental health treatment settings. There was a conscious decision within Clearview that it was important not to artificially limit the numbers of people served in order to keep totally within the parameters of the supported employment implementation research. One of its guiding philosophies is to extend the range of its services not just to people expressing an interest in employment but also to assertively market employment to those who heretofore have not even considered it for themselves. What must be examined further is the equilibrium that must be created between aggressive outreach and losing the ability to properly attend to the multiplicity of needs of the targeted group.

In sum, it appears that the HVP approach has affected the psychiatric rehabilitation, mental health, criminal justice, and homeless service sectors in Clark County, WA quite positively. Given the great needs of the group that the HVP program seeks out, that is, people who are homeless and have mental illness, substance abuse histories, and/or criminal convictions, it is imperative that further efforts be directed to make the project as efficacious as possible. This can be accomplished through program design revisions, staff skills training and knowledge acquisition, more accurate data management, and enhanced continuous quality improvement activities. While much room for improvement still exists in the foreseeable future, there does appear to be a significant impact both in terms of employment results and embryonic structural change within the local mental health system of care in which HVP operates.

\section{ACKNOWLEDGEMENT}

The author wishes to extend his thanks to those who helped in the final preparation of this manuscript including the clients and staff of the Hope, Vocational, Progress program of Vancouver, WA, which includes clients and staff of Columbia River Mental Health Services, Inc., YW Housing, and SHARE House. Also, thanks go to colleagues who offered editorial suggestions: Cori DiBiase of ICI in Boston, MA, David Hoff of the Metro North Regional Employment Board in Cambridge, MA, and Robert Gervey and Ken Gill of UMDNJ.

\section{REFERENCES}

Ball, F.L. \& Havassy, B.E. (1984). A survey of the problems and needs of homeless consumers of acute psychiatric services. Hospital and Community Psychiatry, 35(9), 9-917.

Becker, D.R., Bond, G.R., McCarthy, D., Thompson, D., Xie, H., McHugo, G.J., \& Drake, R.E. (2001). Converting day treatment centers to supported employment programs in Rhode Island. Psychiatric Services, 52, 35I-357.

Becker, D.R., Torrey, W.C., Toscano, R., Wyzik, P.S., \& Fox, T.S. (1998). Building recovery oriented services: Lessons from implementing IPS in community mental health centers. Psychiatric Rehabilitation Journal, 22, 5I-54

Belcher, J.R. \& Ephross, P.H. (1989). Toward an effective practice model for the homeless 
mentally ill. Social Casework, 70, 421-427.

Bond, G.R. (1998). Principles of the individual placement and support model: Empirical support. Psychiatric Rehabilitation Journal, 22(I), 1-11.

Bond, G.R. (2004). Supported employment: Evidence for an evidence based practice. Psychiatric Rehabilitation Journal, 27, 345-359..

Bond, G.R., Drake, R.E., Becker, D.R., \& Mueser, K.T. (1999). Effectiveness of psychiatric rehabilitation approaches for employment of people with severe mental illness. Journal of Disability Policy Studies, 10, 18-52.

Bond, G.R., Picone, J., Mauer, B., Fishbein, S., \& Stout, R. (2000). The quality of supported employment implementation scale. Journal of Vocational Rehabilitation, 14, 201-212.

Burkhauser, R.V., Daly, M.C., \& Houtenville, A.J.C. (2000). How working age people with disabilities fared over the 1990's business cycle. Ithaca, NY: Comell University, Rehabilitation Research and Training Center for Economic Research on Employment Policy for Persons with Disabilities.

Burkhauser, R.V. \& Stapleton, D.C. (2004). The decline in the employment rate for people with disabilities: Bad data, bad health or bad policy. Journal of Vocational Rehabilitation, 20, $185-202$.

Caton, C., Wyatt, R., Grunberg, J., \& Felix, A. (1990). An evaluation of a mental health program for homeless men. American Journal of Psychiatry, 147, 286-289..

Danley, K.S. \& Anthony, W.A. (1987). The choose-get-keep approach to supported employment. American Rehabilitation, 13(4), 3-4, 27-29.

Dooley, D., Catalano, R., \& Wilson, G. (1994). Depression and unemployment: Panel findings from the Epidemiologic Catchment Area study. American Journal of Community Psychology, 22, 745-765..

Drake, R.E., Essock, S.M., Shaner, A., Carey, K.B., Minkoff, K., Kola, L., (200I). Implementing dual diagnosis services for clients with severe mental illness. Psychiatric Services, $52,469-476$.

Hall, L.L., Graf, A.C., Fitzpatrick, M.J., Lane, T., \& Birkel, R.C. (2003). Shattered Lives: Results of a National Survey of NAMI Members Living with Mental Illnesses and Their Families. TRIAD Report. Bethesda, MD: Stanley Medical Research Institute.

Harlow, C.W. (1998). Profile of Jail Inmates 1996, U.S. Department of Justice, Bureau of Justice Statistics (164620). Washington, DC: US Department of Justice.

Johnsen, M., Samberg, L., Calsyn, R., Blasinsky, M., Landow, W., \& Goldman, H. (1999). Case management models for persons who are homeless and mentally ill: The ACCESS Demonstration Project. Community Mental Health Journal, 35, 325-346..

Kasl, S.V., Rodriguez, E., \& Lasch, K.E. (1998). The impact of unemployment on health and well-being. In B.P. Dohrenwend (Ed.), Adversity, stress, and psychopathology (pp. 111-113). New York: Oxford University Press.

Klinkenberg, W. \& Calsyn, R. (1996). Predictors of receipt of aftercare and recidivism among persons with severe mental illness: A review. Psychiatric Services, 47, 487-496.

Lam, J. \& Rosenheck, R. (2000). Correlates of improvement in quality of life among homeless persons with serious mental illness. Psychiatric Services, 51, 116-118.

Lennon, M.C. (1999). Work and unemployment as stressors. In A. Horwitz \& T. Scheid (Eds.), A handbook for the study of mental health: Social contexts, theories and systems (pp. 284-294). New York: Cambridge University Press. 
Long, L. \& Van Tosh, L. (1988). Consumer-run self-help programs serving homeless people with a mental illness (Volume III). Rockville, MD: National Institute of Mental Health.

Lurigio, A.J. (2001). Effective services for parolees with mental illnesses. Crime and Delinquency, 47, 446-461.

Marrone, J. (1993). Creating positive vocational outcomes for people with mental illness. Psychosocial Rehabilitation Journal, 17, 43-62.

Marrone, J. \& Boeltzig, H. (2005). Recovery with results not rhetoric. Report by Institute for Community Inclusion, UMass Boston onPromising Effective Practices, Barriers, and Policy Issues for Promoting the Employment of Persons with Psychiatric Disabilities. Boston: Institute for Community Inclusion

Marrone, J. \& Golowka, E. (2000). If you think work is bad for people with mental illness, then try poverty, unemployment, and social isolation. Psychiatric Rehabilitation Journal, 23, $187-193$.

Marrone, J., Hoff, D., \& Helm, D. (1997). Person-Centered Planning for the millennium: We're old enough to remember when PCP was still a drug. Journal of Vocational Rehabilitation, 8, 285-297.

Marrone, J., Tellier, J., DiGalbo, L., \& Taylor, S. (in press). Systems issues in the provision of psychiatric vocational rehabilitation. In Innovative Practices in Vocational Rehabilitation with People with Psychiatric Disabilities. 30th IRI: George Washington University.

McMurray-Avila, M.M., Gelberg, L., \& Breakey, W.R. (1998). Balancing act: Clinical practices that respond to the needs of homeless people. Washington, DC: Presented at the National Symposium of Homelessness Research, October 29-30, 1998.

MDRC. (2001). Welfare, housing, and employment: Learning from the Jobs-Plus Demonstration. MDRC Policy Brief. Washington, DC: Manpower Development Research Corporation (MDRC)

National Alliance for the Mentally Ill (NAMI). (2001). Study reveals cost to society for housing homeless persons with mental illness is essentially equal to cost of remaining homeless NAMI E-NEWS. May 4, 200I, Alexandria, VA: NAMI.

Oakley, D.A. \& Dennis, D.L. (1996). Responding to the needs of homeless people with alcohol, drug, and/or mental disorders. In J. Baumohl (Ed.), Homelessness In America (pp. 179-186). Phoenix, AZ: Oryx Press

Phillips, S.D., Burns, B.J., Edgar, E.R., Mueser, K.T., Linkins, K.W., Rosenheck, R.A.,. (2001). Moving assertive community treatment into standard practice. Psychiatric Services, $52,771-779$.

President's New Freedom Commission on Mental Health. (2003). Achieving the promise: Transforming mental health care in America. Final report. Pub. No. SMA-03-3832. Rockville, MD: Department of Health and Human Services

Salyers, M.P., Becker, D.R., Drake, R.E., Torrey, W.C., \& Wyzik, P.F. (2004). A ten-year follow-up of a supported employment program. Psychiatric Services, 55, 302-308..

Shaheen, G., Williams, F., \& Dennis D. (Eds.). (2003). Work as a priority: A resource for employing people who have a serious mental illness and who are homeless. DHHS Pub. No. SMA 03-3834. Rockville, MD: Center for Mental Health Services, Substance Abuse, and Mental Health Services Administration.

Sullivan, G., Burnam, A., Koegel, P., \& Hollenberg, J. (2000). Quality of life of homeless persons with mental illness: Results from the course-of-homelessness study. Psychiatric Services, 51, 1135-1141.. 
Urban Institute Report. (1999). Homelessness: Programs and the people they serve: An overview of homeless clients. Washington, DC: Urban Institute.

Wenzel, S., Ebener, P., Koegel, P., \& Gelberg, L. (1996). Drug-abusing homeless clients in California's substance abuse treatment system. Journal of Psychoactive Drugs, 28, 147-159. 